\title{
KRITERIA KELIMPAHAN BAMBU LAUT (Isis hippuris) DI PERAIRAN KONAWE SULAWESI TENGGARA
}

\section{ABUNDANCE CRITERIA OF THE SEA BAMBOO (Isis hippuris) IN THE WATERS OF KONAWE, SOUTHEAST SULAWESI}

\author{
Abdullah', Abdul Rauf ${ }^{2}$, Asbar ${ }^{3}$ \\ 1 Program Studi Manajemen Pesisir dan Teknologi Kelautan, Universitas Muslim Indonesia \\ 2 dan ${ }^{3}$ Dosen Fakultas IImu Kelautan, Universitas Muslim Indonesia \\ ulla.abdull@gmail.com
}

\begin{abstract}
ABSTRAK
Bambu Laut (Isis hippuris) merupakan jenis ikan yang dilindungi berdasarkan periode waktu tertentu (moratorium). Penelitian ini dilaksanakan Bulan September sampai Oktober 2018. Penelitian ini dilakukan dengan tujuan untuk Mengetahui kelimpahan bambu laut (Isis hippuris) di perairan Konawe, Hasil penelitian menunjukkan bahwa : Kelimpahan bambu laut tertinggi pada lokasi Kelurahan Toronipa dengan kategori melimpah. Berturut-turut diikuti lokasi Pulau Bokori kategori banyak, lokasi Desa Wawohara kategori sedang, lokasi Pulau Saponda Laut kategori jarang, lokasi Pulau Saponda Darat kategori jarang.
\end{abstract}

Kata kunci : kelimpahan bambu laut, konawe

\section{ABSTRACT}

Sea Bamboo (Isis hippuris) is a fish species that is protected based on a certain period of time (moratorium). This research was conducted from September to October 2018. This research was conducted with the aim of Knowing the abundance criteria of sea bamboo (Isis hippuris) in the waters of Konawe, The results of this study indicate that: (1). The highest abundance of sea bamboo located in Toronipa Village with overflow categories. Followed by Bokori Island with a lot categories, Wawohara Village medium category, Saponda Laut Island rare category is rare, and Saponda Island Land rare category.

\section{PENDAHULUAN}

Konawe adalah salah satu kabupaten di Provinsi Sulawesi Tenggara yang memiliki potensi sumberdaya pesisir dan laut seperti ekosistem terumbu karang, lamun dan mangrove yang memiliki konstribusi dalam peningkatan sumberdaya perikanan. Selain itu, perairan Kab. Konawe merupakan habitat beberapa jenis biota dilindungi salah satunya adalah Bambu Laut (Isis hippuris).

Pemerintah melalui Kementerian Kelautan dan Perikanan telah menetapkan Keputusan Menteri tentang moratorium bambu laut pada tahun 2014. Perlindungan terhadap satwa ini telah ditetapkan oleh pemerintah yang tercantum dalam KEPMEN-KP No. 46 tahun 2014 tentang Penetapan Status Perlindungan Terbatas Jenis Bambu Laut (Isis spp.) berdasarkan periode waktu tertentu selama 5 (lima) tahun terhitung sejak ditetapkannya Keputusan Menteri Kelautan dan Perikanan ini.

Bambu Laut tergolong hewan yang dalam nama latinnya biasa dikenal Isis hippuris. Klasifikasi bambu laut adalah sebagai berikut: 


$\begin{array}{ll}\text { Kingdom } & \text { : Animalia } \\ \text { Filum } & \text { : Cnidaria } \\ \text { Kelas } & \text { : Anthozoa } \\ \text { Sub Kelas } & \text { : Alcyonaria (Octocoralia) } \\ \text { Ordo } & \text { : Alcyonacea } \\ \text { Sub Ordo } & \text { : Holaxonia } \\ \text { Familli } & \text { : Isididae } \\ \text { Genus } & \text { : Isis }\end{array}$

Spesies: Isis hippuris (Linnaeus, 1758)

Nama Umum : Gorgonian

Bambu laut sebagai komoditas ekonomis penting, sebelum moratorium dieksploitasi secara intensif untuk memenuhi permintaan pasar. Permintaan pasar terbesar adalah dari Cina dan memiliki harga yang tinggi (Berita Antara, 2009). Menurut data Karantina KKP pusat, pada tahun 2011 ekspor Oktokoralian sebesar 230 ton kering dan pada tahun 2012 dan 2013 masing-masing meningkat menjadi 440 ton dan 420 ton kering.

Selain kondisi habitat, tingkat pemanfaatan dialam, Kriteria kelimpahan merupakan salah satu parameter penting yang berkonstribusi dalam penetapan staus perlindungan bambu laut.

\section{METODOLOGI PENELITIAN}

Penelitian ini dilaksanakan pada Bulan September - Oktober 2018 yang berlokasi di Perairan Konawe Sulawesi Tenggara.

Metode yang digunakan dalam Pengambilan data bambu laut menggunakan metode sapuan wilayah (sweept area) yang biasa disebut transek sabuk (belt transect). Transek sabuk sepanjang $50 \mathrm{~m}$, lebar pengamatan kiri dan kanan masing-masing $5 \mathrm{~m}$, sehingga luas total areal pengamatan $500 \mathrm{~m}^{2}$ tiap transek (Gambar 1). Meteran ditarik sepanjang 50 meter oleh seorang penyelam kemudian diikuti oleh penyelam berikutnya untuk mengamati, menghitung jumlah dan mengukur lebar koloni bambu laut yang ditemukan dalam traksek sabuk.

Pencatatan jumlah koloni dilakukan sebanyak 2 kali yakni pada daerah reef flat dan reef slope, selain jumlah koloni juga dilakukan pengukuran koloni berdasarkan pengelompokan ukuran yaitu 10-30 cm, 30$50 \mathrm{~cm}$, dan lebih dari $50 \mathrm{~cm}$ (Sadili, Sarmintohadi, Ihsan dalam Pedoman Umum Monitoring Bambu Laut, 2015).

Untuk mempermudah dalam
merecord data pengambilan foto/
dokumentasi dalam pengamatan sangat
diperlukan.

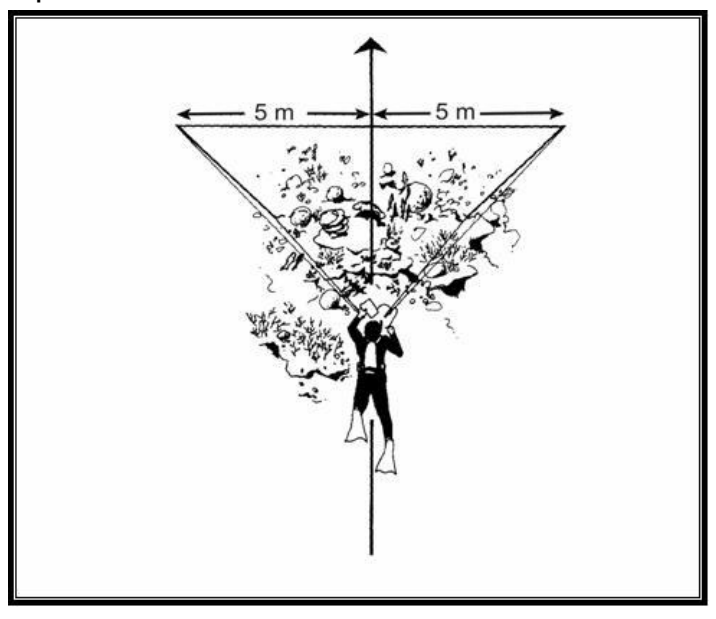

Gambar 1. Model metode transek sabuk yang digunakan

Setiap melakukan pengamatan bambu laut pada setiap stasiun dilakukan pengukuran parameter kualitas air dan oceanografi di perairan secara insitu.

Kelimpahan di analisis dengan cara menghitung jumlah koloni per luasan transek disetiap stasiun pengamatan, dengan kata lain bahwa nilai kelimpahan merupakan jumlah bambu laut yang ditemukan tiap transek $\left(500 \mathrm{~m}^{2}\right)$.

Penentuan kriteria kelimpahan berdasarkan rujukan kriteria kelimpahan 
oleh Haris, A. Tuwo, dan A. Anna, (2010), sebagaimana pada tabel berikut :

Tabel 1. Kriteria Kelimpahan Bambu Laut

\begin{tabular}{|c|c|c|}
\hline No. & $\begin{array}{c}\text { Kelimpahan } \\
\text { (Jumlah Koloni)/ } \\
500 \mathrm{~m}^{2}\end{array}$ & Kategori \\
\hline 1. & $3-44$ & Jarang \\
\hline 2. & $45-84$ & Sedikit \\
\hline 3. & $85-126$ & Sedang \\
\hline 4. & $127-167$ & Banyak \\
\hline 5. & $168-209$ & Melimpah \\
\hline
\end{tabular}

HASIL DAN PEMBAHASAN

\section{Kulaitas Air dan Oceanografi}

Beberap parameter kualitas air dan oceanografi yang diamati diantaranya suhu, salinitas, arus, dan transparansi. Hasil pengambilan data kondisi perairan sesuai dengan lokasi pengamatan Bambu Laut di perairan Kab. Konawe dapat disajikan pada Tabel berikut :

Tabel 2. Data Hasil Pengambilan Kondisi Perairan

\begin{tabular}{|c|c|c|c|c|c|c|}
\hline \multirow[b]{2}{*}{ No. } & \multirow[b]{2}{*}{ Stasiun } & \multirow[b]{2}{*}{ Lokasi } & \multicolumn{4}{|c|}{ Kualitas air } \\
\hline & & & $\begin{array}{l}\text { Suhu } \\
\left({ }^{\circ} \mathrm{C}\right)\end{array}$ & $\begin{array}{c}\text { Salinitas } \\
(0 / 00)\end{array}$ & $\begin{array}{l}\text { Arus } \\
(\mathrm{m} / \mathrm{s})\end{array}$ & $\begin{array}{c}\text { Transparancy } \\
(\%)\end{array}$ \\
\hline 1. & I & Pulau Bokori & 29 & 31 & 0.33 & 100 \\
\hline 2. & II & $\begin{array}{l}\text { Kelurahan } \\
\text { Toronipa }\end{array}$ & 30 & 32 & 0.33 & 100 \\
\hline 3. & III & $\begin{array}{l}\text { Desa } \\
\text { Wawohara }\end{array}$ & 29 & 30 & 0.33 & 100 \\
\hline 4. & IV & $\begin{array}{l}\text { Pulau } \\
\text { Saponda } \\
\text { Laut }\end{array}$ & 30 & 31 & 0.32 & 100 \\
\hline 5. & V & $\begin{array}{l}\text { Pulau } \\
\text { Saponda } \\
\text { Darat }\end{array}$ & 29 & 30 & 0.32 & 100 \\
\hline
\end{tabular}

Sumber: Hasil Analisis Data 2018

Berdasarkan Tabel hasil pengambilan data kondisi perairan di setiap lokasi pengamatan Bambu Laut, dimana secara keseluruhan lokasi pengamatan sesuai dengan kondisi pertumbuhan Bambu Laut. Hal ini dapat dilihat dari kondisi suhu yang diperoleh dengan kisaran $29-30{ }^{\circ} \mathrm{C}$, dimana umumnya terumbu karang keras dan lunak dapat tumbuh dengan kisaran 18-36 'C (Birkeland, 1997) sedangkan menurut Haris (2010) bahwa kisaran suhu yang sesuai dengan kondisi pertumbuhan optimal Bambu Laut berkisar antara 23-
$30{ }^{\circ} \mathrm{C}$. parameter suhu permukaan air laut disemua stasiun pengamatan di perairan Konawe masih sesuai dengan baku mutu air laut menurut Keputusan Menteri Lingkungan Hidup No. 51 Tahun 2004 yaitu untuk ekosistem karang dengan kisaran 28$30^{\circ} \mathrm{C}$.

Salinitas perairan dilokasi pengamatan Bambu Laut berkisar antara 30-32 \% sesuai dengan pertumbuhan bambu laut, sebagaimana yang dikemukakan oleh Haris (2010) bahwa kisaran salinitas yang sesuai dengan 
pertumbuhan optimal Bambu Laut berkisar antara $30-35 \%$.

\section{Kondisi Habitat}

Pengamatan karang di Konawe dilakukan di 5 stasiun/ lokasi dengan menggunakan metode Under Water Photo Transek (UPT) dan diolah dengan menggunakan perangkat lunak $\mathrm{CpCe}$. Hasil pengolahan data didapatkan bahwa kondisi karang di tiap stasiun pengamatan berada dalam kondisi buruk sampai baik. Kondisi karang pada kategori baik berada pada lokasi Pulau Bokori dan Kelurahan Toronipa dengan masing-masing tutupan karang keras hidup sebesar $58.13 \%$ dan $54.97 \%$, sedangkan kondisi karang buruk berada pada 3 (tiga) lokasi pengamatan lainnya yakni Desa Wawohara (13.6 \%), Pulau Saponda Laut $(24.83 \%)$, dan Pulau Saponda Darat $(20.37 \%)$. Adapun data tutupan karang keras hidup selengkapnya dapat dilihat pada gambar dibawah ini.

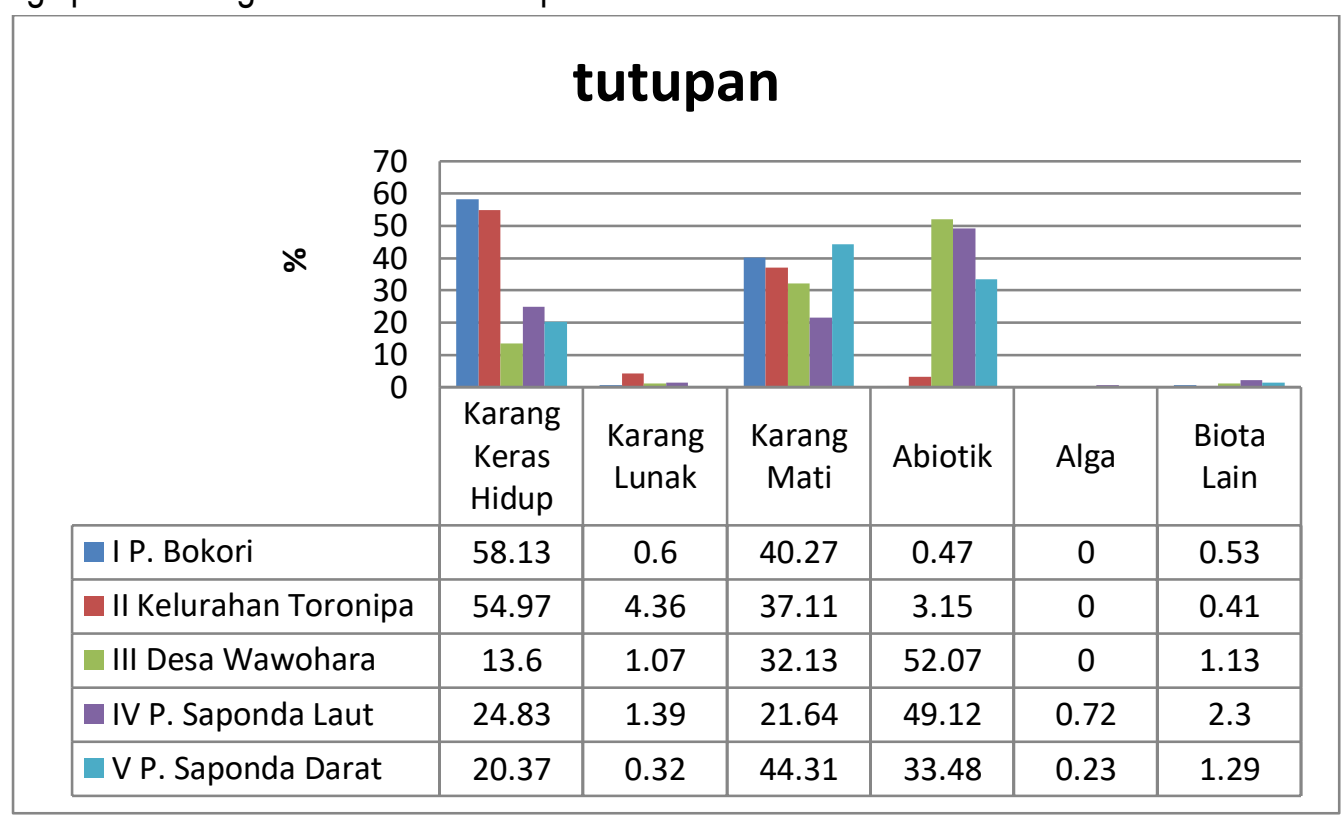

Gambar 2. Grafik Tutupan Karang

Tutupan kategori karang lunak tertinggi didapatkan pada lokasi Krlurahan Toronipa (4.36 \%) dan terendah pada lokasi Pulau Bokori (0.6\%), kategori karang mati paling tinggi pada lokasi Pulau Saponda Darat $(44.31 \%)$ dan terendah pada lokasi Pulau Saponda Laut, tutupan kategori abiotik tertinggi pada lokasi Desa Wawohara (52.07 \%) dan terendah pada lokasi Pulau Bokori $(0.47 \%)$, tutupan kategori alga tertinggi pada lokasi Pulau Saponda Laut (0.72) dan tidak dijumpai pada lokasi Pulau Bokori dan Desa Wawohara.
Tutupan kategori abiotik pada lokasi Wawohara sangat tinggi (52.07 \%) dimana sebaran tutupan karang didominasi oleh pasir dan pecahan karang (rubble), hal ini disebabkan karena lokasi pengamatan karang di perairan Waworaha tepat berada dalam kawasan alat tangkap Sero yang dipasang oleh nelayan setempat, dengan posisi ditengah-tengah alat tangkap Sero kemungkinan besar tekanan pemanfaatan sumberdaya pada ekosistem terumbu karang sangat tinggi sehingga berdampak pada kerusakan ekosistem karang dan biota lainnya. 
Kondisi terumbu karang di perairan Kab. Konawe tidak merata disemua lokasi degan tutupan mulai dari buruk/ rusak sampai dengan kondisi baik. Hal ini disebabkan karena sebagian besar perairairan Kab. Konawe tidak masuk dalam Pencadangan Kawasan Konservasi Perairan Daerah (KKPD) Sulawesi Tenggara, sehingga tidak ada upaya perlindungan kawaan maupun biota dengan demikian berdampak pada kerusakan ekosistem dan biota karena penggunaan alat tangkap yang merusak seperti bom dan bius. Disamping itu, kematian karang juga disebabkan oleh Bintang Laut (Acanthaster planci) yang menyebabkan keputihan terhadap karang.

\section{Kelimpahan Bambu Laut}

Kelimpahan merupakan jumlah bambu laut yang ditemukan tiap transek $\left(500 \mathrm{~m}^{2}\right)$. Kelimpahan bambu laut hasil analisis dapat dilihat pada tabel berikut.

Tabel 9. Kelimpahan Bambu Laut Tiap Stasiun.

\begin{tabular}{|c|c|c|c|c|c|c|}
\hline \multirow{2}{*}{ No. } & \multirow{2}{*}{ Stasiun } & \multirow{2}{*}{ Lokasi } & \multicolumn{3}{|c|}{$\mathrm{Ind} / 500 \mathrm{~m}^{2}$} & \multirow{2}{*}{$\begin{array}{c}\text { Kriteria } \\
\text { Kelimpahan }\end{array}$} \\
\hline & & & flat & slop & Jumlah & \\
\hline 1. & I & Pulau Bokori & 131 & 11 & 142 & banyak \\
\hline 2. & \|I & $\begin{array}{c}\text { Kelurahan } \\
\text { Toronipa }\end{array}$ & 71 & 171 & 242 & melimpah \\
\hline 3. & III & $\begin{array}{c}\text { Desa } \\
\text { Wawohara }\end{array}$ & 65 & 21 & 86 & sedang \\
\hline 4. & IV & $\begin{array}{c}\text { Pulau } \\
\text { Saponda Laut }\end{array}$ & 11 & 20 & 31 & jarang \\
\hline 5. & V & $\begin{array}{c}\text { Pulau } \\
\text { Saponda } \\
\text { Darat }\end{array}$ & 7 & 12 & 19 & jarang \\
\hline
\end{tabular}

Sumber: Hasil Analisis Data 2018

Kelimpahan bambu laut tertinggi pada stasiun II lokasi Kelurahan Toronipa dengan jumlah individu bambu laut sebanyak 242, nilai ini masuk kategori melimpah. Berturut-turut dikuti oleh stasiun I lokasi Pulau Bokori sebanyak 142 (kategori banyak), stasiun III lokasi Desa Wawohara sebanyak 86 individu (kategori sedang), stasiun IV lokasi Pulau Saponda Laut sebanyak 31 individu (kategori jarang), dan stasiun V lokasi Pulau Saponda Darat sebanyak 19 individu (kategori jarang). Grafik kelimpahan bambu laut hasil analisis dapat dilihat pada gambar berikut. 


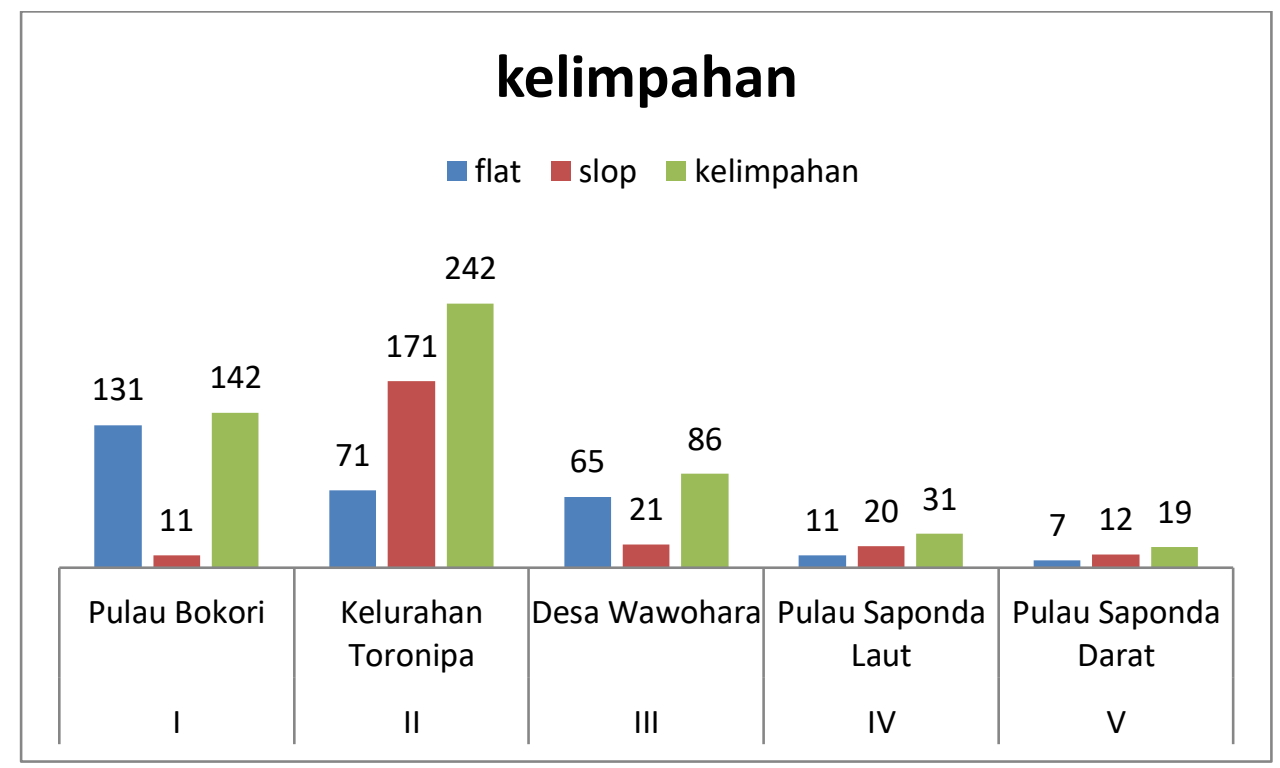

Gambar 3. Kelimpahan Bambu Laut Tiap Stasiun

Kelimpahan bambu laut pada

Pulau Bokori dan Kelurahan toronipa tergolong tinggi dan pada kriteria kelimpahan banyak dan melimpah karena pada kedua lokasi ini kondisi karang yang merupakan habitat bambu laut masih dalam kategori baik dengan nilai tutupan karang keras hidup $58.13 \%$ di Pulau Bokori dan $54.97 \%$ di Kelurahan Toronipa, disamping itu disebabkan oleh paremeter kualitas air yang sesuai dengan pertumbuhan bambu laut baik suhu, salinitas, arus, dan tranparansi. Hal menarik terjadi di Kelurahan Toronipa dimana jumlah individu bambu laut yang ditemukan lebih banyak dibanding Pulau bokori dengan kondisi karang yang sama pada kategori baik dan kualitas air yang sesuai, hal ini besar kemungkinan disebabkan oleh karena pada lokasi Kelurahan Toronipa terdapat barrier reef di dekat lokasi pengamatan bambu laut, dengan demikian pengaruh gelombang yang kuat pada bambu laut dapat terhindarkan. Sebagaimana yang dikemukakan oleh Fabricius dan Alderslade, 2001 bahwa Gorgonia terbatas pada daerah yang terbuka dari arus. Komunitas Isididae di daerah dangkal, dibatasi oleh adanya energi gelombang yang besar terutama pada daerah menghadap angin (wind ward), sehingga menyebabkan rendahnya kelimpahan serta jumlah spesies dari karang ini. Isididae banyak terdapat pada daerah yang terlindung dari gelombang yaitu di sekitar daerah belakang terumbu atau daerah reef slope. Lebih lanjut dijelaskan umumnya tersebar luas diperairan dangkal yang jernih. Di Great Barrier Reef, karang jenis ini biasanya terdapat pada bagian mid-shelf terumbu karang, ditemukan di perairan dangkal yang aman dari aksi gelombang.

\section{KESIMPULAN}

Kelimpahan bambu laut di peraiaran Konawe pada lokasi Kelurahan Toronipa termasuk kategori melimpah, lokasi Pulau Bokori kategori banyak, lokasi Desa Wawohara kategori sedang, lokasi Pulau Saponda Laut kategori jarang, dan lokasi Pulau Saponda Darat kategori jarang.

\section{Ucapan Terima Kasih \\ Ucapan terima kasih yang tak terhingga untuk kedua orang tua, istri}


tercinta, dan putra putri kebanggaan atas pengorbanan, keikhlasan, doa, dan semangat yang terus diberikan kepada penulis. Terima kasih pula penulis sampaikan kepada Bapak Dr. Ir. H. Abdul Rauf, M.Si dan Bapak Dr. Asbar, M.Si selaku dosen pembimbing yang telah membimbing penulis.

\section{DAFTAR PUSTAKA}

Benayahu Y., 1995. Faunistic Composition and Patterns in the Distribution of Soft Coral (Octocorallia Alcyonacea) Along the Coral Reefs of SinaiPeninsula. Proceedings of the Fifth International Coral Reef Congress, Tahiti.

Berita Antara. 2009. Ribuan kilogram bambu laut ditahan di Toli-Toli. Rabu, 8 September 2009.

Birkeland C., 1997. Life and Death of Coral Reefs. International Thomson Publishing, University of Guam, New York USA.

BPSPL Makasar. 2012. Status Populasi dan Pemanfaatan Isis hippuris di Pulau Sulawesi. Review Survei. Balai Pengelolaan Sumberdaya Pesisir dan Laut. Dirjen KP3K-KKP. 24 hal.

Cesar.H., 1996. Economic analysis on Indonesia coral reef. The World Bank, Indonesia.

Dit. KKHL, 2010. Pedoman Umum Monitoring Bambu Laut.

Edrus, I.N. \& Suman, A. 2013. Kebijakan Perlindungan dan Konservasi Hewan Oktokoralian/Bambu Laut (Isis hippuris Linnaeus 1758). J. Kebijak. Perikan. Ind. Vol.5 (2): 107 $-112$
Effendi H., 2003. Telaah Kualitas Air Bagi Pengeloloaan Sumberdaya dan Lingkungan Perairan. Kanisius, Yogyakarta.

Fabricius M. dan P. Alderslade, 2006. Soft Coral and Sea Fans. Reading Trees Publications. USA. $141 \mathrm{p}$.

Haris, A., A. Tuwo, A. Annas, 2010. Kelimpahan dan Distribusi Isis hippuris di Perairan Spermonde, Kota Makassar.

Nybakken J.W., 1992. Biologi Laut; Suatu Pendekatan Ekologis. Penerbit Gramedia. Jakarta. 